\title{
COVID-19 ve Sağlık Hizmeti Sunulan Merkezlerde Enfeksiyon Kontrol Önlemleri
}

\section{COVID-19 and Infection Control Measures in Health Care Centers}

\section{Arzum ÇELIK BEKLEVIC}

Bülent Ecevit Üniversitesi, Ahmet Erdoğan Sağlık Meslek Yüksekokulu, Tıbbi Hizmetler ve Teknikerler Bölümü, Ameliyathane Hizmetleri Pr., Zonguldak, Türkiye

ORCID ID: Arzum Çelik Bekleviç 0000-0002-9989-8599

Bu makaleye yapılacak atıf: Çelik Bekleviç A. COVID-19 ve Sağlık Hizmeti Sunulan Merkezlerde Enfeksiyon Kontrol Önlemleri. Med J West Black Sea. 2021;5(2):125-131.

Sorumlu Yazar

Arzum Çelik Beklevic

E-posta

arzum.cb@beun.edu.tr
Geliș Tarihi

14.03.2021

Revizyon Tarihi

20.04.2021

Kabul Tarihi

22.04.2021 öz

Çin'in Wuhan kentinde ortaya çıkan ve büyük bir küresel salgına neden olan yeni tip koronavirüs, insanlarda hastalık etkeni olarak tanımlanmış ve Dünya Sağlık Örgütü (DSÖ) tarafından 11 Mart 2020 tarihinde pandemi olarak ilan edilmiştir. Koronavirüs hastalığı (Coronovirus Disease-19, COVID-19) olarak isimlendirilen hastalığa, enfekte bireylerin solunum sekresyonlarında yoğun olarak bulunan SARS-CoV-2 virüsü neden olmaktadır. İnsanlar arasında bulaş, enfekte bireyin sekresyonlara doğrudan maruziyet, enfekte kişi ile yakın temas ya da enfekte yüzeylere temas sonucu gerçekleşmektedir. Pandemide hastalar belirti bulguların ortaya çıkmasının ardından ilk olarak sağlık merkezlerine başvurmaktadırlar. Sağlık merkezlerinde oluşan yoğunluk, hastalığın yayılımı ve bulaşı açısından oldukça yüksek risk taşımaktadır. Temel hedef hastaların, hasta yakınlarının ve sağlık personellerinin sağlığının korunmasıdır. Bu bağlamda hastane kaynaklı transmisyonların önlenmesi amacı ile etkin enfeksiyon kontrol önlemlerinin uygulanması çok önemlidir. Sağlık hizmeti veren merkezlerde, enfeksiyon kontrol önlemleri programını, Enfeksiyon Kontrol Komiteleri (EKK) hazırlar ve hastane yönetimi uygular. Araştırmalar, enfeksiyon kontrol önlemleri programlarının bulaşıcı hastalıkların yayılmamasında ve çalışan sağlığının korunmasında etkili olduğunu göstermektedir. Bu nedenle enfeksiyon kontrol önlemleri, çalışanlar tarafından bilinmelidir ve doğru uygulanmalıdır. COVID-19 pandemisinde, ulusal ve uluslararası rehberlerin önerileriyle oluşturulan enfeksiyon kontrol programı, kurumun stratejik planları, ünitelerin fiziksel yapıları ve ișleyiș özellikleri dikkate alınarak hazırlanmalıdır. Bu bağlamda, enfeksiyon kontrol programı genel hatları ile "hastaların tanı/tedavi süreçlerini, çalışan sağlığının korunmasını, alanda görevlendirilecek personel dağılımını ve merkezlerde uyulması gereken enfeksiyon kontrol önlemleri" konularını içermelidir.

Anahtar Sözcükler: Covid-19, Enfeksiyon kontrol önlemleri, Pandemi eylem planı

\section{ABSTRACT}

The new type of coronavirus, which originated in Wuhan, China and caused a major global epidemic, was defined as a disease factor in humans and was declared as a pandemic by the World Health Organization (WHO) on March 11, 2020. The disease, called COVID-19, is caused by the SARS-CoV-2 virus, which is densely found in respiratory secretions of infected individuals. Transmission between humans occurs as a result of direct exposure of the infected individual to secretions, close contact with the infected person, or contact with infected surfaces. Pandemic patients first apply to health centers after the emergence of symptoms. The density that occurs in health centers carries a very high risk in terms of the spread and transmission of the disease. In the pandemic, it is very important to implement effective infection control measures in order to protect the health of patients, patients' relatives and healthcare personnel and to prevent hospital-borne transmissions. Infection control measures are prepared by Infection Control Committees and hospital management is implemented. Studies show 
that infection control is effective in preventing the spread of infectious diseases and protecting employee health. Therefore, infection control measures should be known by employees and applied correctly. In the COVID-19 pandemic, the infection control program created with the recommendations of national and international guidelines should be prepared by taking into account the strategic plans of the institution, the physical structures and functioning features of the units. In this context, the infection control program should generally include the issues of "diagnosis / treatment processes of patients, protection of employee health, distribution of personnel to be assigned in the field and infection control measures to be followed in centers".

Keywords: Covid-19, Infection Control Programe, Pandemic action plan

\section{Giriș}

2019 yılının sonunda Çin'in Wuhan kentinde ortaya çıkan ve büyük bir küresel salgına neden olan yeni tip koronavirüs insanlarda hastalık etkeni olarak tanımlanmış ve Dünya Sağlık Örgütü (DSÖ) tarafından 11 Mart 2020 tarihinde pandemi olarak ilan edilmiştir. Enfekte bireylerin solunum sekresyonlarında yoğun olarak bulunan SARS-CoV-2 virüsünün neden olduğu hastalık, COVID-19 olarak isimlendirilmiştir. İnsanlar arasında bulaş temel olarak üç şekilde gerçekleşmektedir. Virüs, enfekte bireyin sekresyonlara doğrudan maruziyet, enfekte kişi ile yakın temas ya da enfekte yüzeylere temas sonucu bulaşmakta ve yayılmaktadır $(1,2)$. Pandemide hastalar belirti bulguların ortaya çıkmasının ardından tanı ve tedavi süreçlerinin tamamlanması ve iyileşmek amacı ile ilk olarak sağlık merkezlerine başvurmaktadırlar. Sağlık merkezlerinde oluşan yoğunluk, hastalığın yayılımı ve bulaşı açısından oldukça yüksek risk taşımaktadır. Bu nedenle, pandemi döneminde hastaların, hasta yakınlarının ve merkezlerde çalışan sağlık personellerinin sağlığının korunması ve hastane kaynaklı transmisyonların önlenmesi amacı ile etkin enfeksiyon kontrol önlemlerinin uygulanması kritik öneme sahiptir $(3,4)$.

Ülkemizde, hastanelerin Enfeksiyon Kontrol Komiteleri (EKK) nozokomiyal enfeksiyonların önlenmesinde ve "Enfeksiyon Kontrol Programının" oluşturulmasında aktif rol üstlenmektedirler (5). EKK' leri bir salgın hastalığın ortaya çıkması durumuna yönelik enfeksiyon kontrol programı hazırlarken, salgının boyutunu, şiddetini, bulaşma şeklini, yayılım hızını ve toplumda görülme sıklığını dikkate almalı ve kurumun stratejik planlarını, ünitelerin fiziksel yapılarını ve işleyiş özelliklerini (kurumdaki insan gücü, malzeme ve ekipman sayısı, yoğun bakım üniteleri ve kliniklerdeki yatak sayısı gibi) göz önünde bulundurmalıdır $(3,4)$.

COVID-19 pandemisine yönelik, ulusal ve uluslararası rehberler ışığında oluşturulan enfeksiyon kontrol programı aynı zamanda "Pandemi Eylem Planı" olarak tasarlanmalı ve genel olarak, "hastaların tanı/tedavi süreçlerini, çalışan sağlığının korunmasını, personel dağılımını ve merkezlerde uyulması gereken enfeksiyon kontrol önlemleri” gibi konuları içermelidir $(3,6,7)$.

\section{Sağlık Merkezlerinde Enfeksiyon Kontrol Önlemleri - COVID-19}

COVID-19 şüphesiyle sağlık merkezlerine başvuran hastaların tanı ve tedavi sürecinin kontrolünün sağlanması amacı ile; ayaktan tanı ve tedavi işlemleri için(muayene odası, kan alma ünitesi, EKG çekim ünitesi, radyolojik tetkik ünitesi vb.) poliklinikler, yatarak tanı ve tedavi işlemleri için klinikler, kritik durumu olan hastaların tanı ve tedavi işlemleri için yoğun bakım ünitesi, acil durum başvuruları için acil ünitesi, müdahale ve operasyon gerekliliği durumunda ameliyathane ünitesi belirlenmelidir (7). Pandemi durumunda karşımıza çıkan en önemli husus çalışan sağlığının korunmasıdır. SARS-CoV-2 etkenine yönelik, çalışan sağlığının korunmasının birincil basamağı nozokomiyal bulaşın önlenmesinin sağlanmasıdır. Bu bağlamda literatür incelendiğinde, hastalarda ve sağlık çalışanlarında nozokomiyal enfeksiyonların bulaş riskini ortadan kaldırılması için, standart önlemler ve izolasyon kurallarına uyulmasının ve çevresel temizlik ilkelerinin uygulanmasının son derece etkili olduğu görülmüştür $(4,6,8)$.

\section{Standart Önlemler ve İzolasyon}

Standart önlemler; her bireyin potansiyel enfekte olduğunu ve/veya enfeksiyon yapabilecek bir patojen ile kolonize olduğunu varsayarak alınan önlemlerdir (3). İzolasyon ise, standart önlemlere ek olarak hastanın ve sağlık personelinin bilinen enfeksiyonun bulaş yoluna yönelik aldığı önlemlerdir (3). COVID-19 hastalığının insandan insana bulaşı temel olarak; enfekte bireyin öksürme, aksırma ya da konuşma esnasında solunum sekresyonlarına doğrudan maruziyet veya enfekte bireyin kontamine ettiği çevresel yüzeylere temas edildikten sonra ellerin (hijyeni sağlanmadan) ağız, burun ve göze teması sonucu gelişmektedir $(1,7)$. Bu nedenle, sağlık merkezlerinde bireylerin standart önlemlerin -özellikle el hijyeni uygulamalarının- esas alınarak, temas ve damlacık izolasyonu önlemlerine uyması ve kişisel koruyucu ekipman kullanımı SARS-CoV-2 ile mücadelenin temelini oluşturmaktadır (1-3,7).

Temas ve damlacık izolasyonu kriterlerine göre, hastaların tanı ve tedavi süreçlerinin tek kişilik odalarda (banyosu ve tuvaleti içeride) sağlanması gerekmektedir (1-3,7). Tek kişilik oda olanağı sağlanamayan sağlık merkezlerinde, zorunlu durumlar için, kohort uygulaması önerilmektedir $(2,3)$. 
COVID-19 hastalığına ilişkin merkezlerde yapılan kohortlama, SARS-CoV-2 ile enfekte olan, kültür sonucu pozitif gelen hastaların, aynı odada aralarında en az 1-1,5 metre mesafe olacak şekilde takip edilmesidir $(2,3,7)$. Test sonucu belli olmayan hastaların da sonuçları öğrenilene kadar enfekte hasta ile aynı odada olmaması, tek kişilik odalarda takip edilmesi öneriler arasında yer almaktadır (7).

Literatür incelendiğinde, standart önlemlerin temelinin ve bulaşıcı hastalıklardan korunmanın en etkili yolunun el hijyeni uygulamaları olduğu görülmektedir (2- 4,7-10). Sağlık merkezlerinde patojen mikroorganizmalar ile kontaminasyonun (mikroorganizma yükünün azaltılması, çapraz bulaşın önlenmesi vb.) engellenmesi için el hijyeni uygulanmalarının etkin yapılması son derece önemlidir. Bu bağlamda el hijyeni uygulamalarının etkin olabilmesi için "5 Endikasyon Kuralı"na uyulması gerekmektedir (8,10). 5 Endikasyon Kuralı; "hasta ile temas etmeden önce, temas ettikten sonra, aseptik işlemlerden önce, hastanın çevresi ile temastan önce ve hastanın vücut sıvı/salgıları ile kontaminasyondan sonra" el hijyeninin sağlanmasıdır $(3,7,8)$.

\section{a) EI Hijyeni}

El hijyeni, su ve sabun ile el yıkama ve/veya antiseptik ajanlar ile el ovalama yapılarak sağlanmaktadır (8,9). Ellerde bulunan mikroorganizma yükünün azaltılmasına olan etkisi açısından değerlendirildiğinde her iki uygulamanın da (elleri su ve sabunla yıkamak ve/veya alkol bazlı el antiseptiklerini kullanarak elleri ovalama) etkili olduğu, birbirine üstünlüğü olmadığı görülmektedir $(9,11)$. Bu nedenle sağlık personellerinin yoğun iş yükü içerisinde zamandan tasarruf etmek amacı ile el hijyeni uygulamalarında (ellerde gözle görünür kirlilik yoksa) antiseptik ajanlar ile el ovalamayı tercih etmelerinde herhangi bir sakınca bulunmadığı düşünülmektedir.

El yıkama; hijyenik el yıkama ve cerrahi el yıkama olarak, yıkama şekline ve süresine göre isimlendirilmiştir. Cerrahi el yıkama ameliyat öncesi sağlık çalışanlarının ellerinde bulunan patojen/patojen olmayan mikroorganizmaların uzaklaştırılması için, hijyenik el yıkama ise ameliyathane dışında hasta bakım alanlarının tamamında ellerde bulunan patojen mikroorganizmaların uzaklaştırılması için uygulanan yöntemdir (9-11). Hijyenik el yıkama geçici flora patojenlerini hedef alırken, cerrahi el yıkama hem geçici floranın tama-

\begin{tabular}{|c|c|c|c|c|}
\hline $\begin{array}{l}\text { Eller su ile } \\
\text { Islatılır }\end{array}$ & & $\begin{array}{l}\text { Elin tüm } \\
\text { yüzeyi* } \\
\text { sabunlanır }\end{array}$ & & $\begin{array}{l}\text { Kağıt havlu ile } \\
\text { tam olarak } \\
\text { kurulanır }\end{array}$ \\
\hline & $\begin{array}{l}\text { Avuç içine } \\
\text { 3-5ml sabun } \\
\text { alınır }\end{array}$ & & $\begin{array}{l}\text { Eller su ile } \\
\text { durulanır }\end{array}$ & \\
\hline
\end{tabular}

Şekil 1: Hijyenik el yıkama basamakları

* elin tüm yüzeyi, avuç içi, el sırtı, parmak araları, parmak uçlarıtırnak dipleri, baş parmak ve el bileği kısımlarını içerir. mını hem de kalıc floranın bir kısmındaki patojenleri hedef almaktadır (11).

Hijyenik el yıkamada eller, akan su altında ıslatılmalı, 3-5 ml sabun ile en az 25-30 sn sabunlanarak ovalanmalı, durulanmalı ve tek kullanımlık kağıt havlu ile kurulanmalıdır. Kullanılan kağıt havlu ayakla çalışan kapaklı çöp kutularına atılmalıdır (Şekil 1) $(10,11)$.

Antiseptikli ajanlar ile el ovalama ise ellerin, alkol bazlı el antiseptikleri kullanılarak patojen mikroorganizmalardan arındırılması işlemidir. El hijyeni ile ilgili kılavuzlar incelendiğinde, ABD Hastalık Kontrol ve Önleme Merkezi (CDC) ve DSÖ, uygun cilt antisepsisinin sağlanabilmesi için, \%60' dan fazla etanol veya \%70 izopropanol içeren alkol bazlı solüsyonlar kullanılmasını ve ellerin, antiseptikler cilt yüzeyinde kuruyana kadar, ovalanmasının önermektedir (Şekil 2) $(8,10)$. Her iki uygulamada da temel olan ellerin tüm yüzeyinin (avuç içleri, el sırtı, parmak uçları, parmak araları, baş parmak ve bilekler) sabun/antiseptikler ile temas etmesinin sağlanmasıdır.

\section{b) Kişisel Koruyucu Ekipman (KKE) Kullanımı}

Patojen mikroorganizmaların bulaşını önlemeye yönelik alınan standart önlemlerin bir diğer önemli basamağı da sağlık çalışanlarının kişisel koruyucu ekipman kullanılmasıdır. DSÖ, CDC, Avrupa Hastalık Kontrol ve Önleme Merkezi (ECDC), T.C. Sağlık Bakanlığı Halk Sağlığı Genel Müdürlüğü (HSGM), COVID-19 hastalığına ilişkin sağlık personelinin korunması amacı ile kişisel koruyucu ekipman (KKE) kullanımı önermektedir $(1,7,12,13)$. Kesin/olası COVID-19 vakalarının muayene, tedavi ve bakımı esnasında temas ve damlacık izolasyon önlemlerine uygun olarak, KKE kullanılması son derece önemli bir korunma yoludur $(1,7,13)$. Temas ve damlacık izolasyonuna alınan hastaların tanı ve tedavi sürecinde, hem personel sağlığının hem de hasta ve refakatçi sağlığının korunması amacıyla -izolasyona özelkişisel koruyucu ekipman kullanmalıdır $(12,14)$.

CDC, ECDC, DSÖ ve HSGM, COVID-19 hastalarının tanı ve tedavisinde kişisel koruyucu ekipman olarak; eldiven, önlük, gözlük/siperlik, maske (tıbbı/cerrahi maske ve partikül tutucu maske (ffp2/N95 veya ffp3/N99), bone ve gerekli durumlarda (yoğun vücut sıvı-sekresyon kontaminasyonu ihtimali vb.) da koruyucu tulum gibi ekipmanların kullanılması-

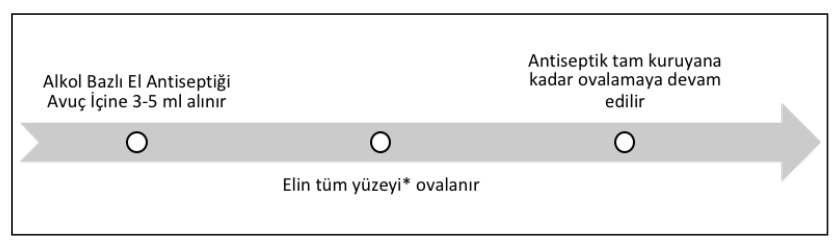

Şekil 2: Alkol bazlı El antiseptikleri ile el ovalama

* elin tüm yüzeyi, avuç içi, el sırtı, parmak araları, parmak uçlarıtırnak dipleri, baş parmak ve el bileği kısımlarını içerir. 
nı önermektedir (7,15-17). Ayrıca, kontaminasyon ve bulaş riskini en aza indirmek amacı ile KKE'lerin belirli bir sıra ile giyilip ve çıkarılmasını ve tüm personelin belirlenen bu sıraya uyum göstermesi gerektiğini ifade etmektedir $(8,15,16)$. Bu öneriler doğrultusunda, sağlık merkezlerinde çalışanlar, hasta odasına girmeden önce el hijyeni sağlamalı ve sırasına uygun olarak; tulum (opsiyonel-hastaya uygulanacak işleme göre), önlük, maske, bone, gözlük/siperlik ve eldiven giyinmelidir. Hasta odasından çıkarken yine sırasına uygun olarak; önce eldiven, gözlük gözlük/yüz siperliği, önlük ve en son maskesini çıkarmalıdır. Çıkarılan her ekipmanın ardından el hijyeni uygulaması yapılmalı ve el kontaminasyonu önlenmelidir $(7,11,18)$. Rehberlerde, hastaya yapılan işleme (SARS-CoV-2 ile kontaminasyon riskinin büyüklüğüne) göre KKE çıkarılırken, gözlük/siperlik ve önlük çıkarılması sırasının yer değiştirebileceği de belirtilmiştir (15). Buna ek olarak ekipman çıkartılırken, bireyin hem kendisini hem de çevresel yüzeyleri kontamine etme riskine dikkat çekilerek, kullanılan KKE'lerin ön yüzeylerine elle temas edilmemesi ve KKE'lerin arka/dış yüzeylerinden tutularak çıkartılması gerektiği vurgulanmaktadır (14-16). Bu noktada kurumlar KKE kullanımı politikalarını oluştururken kılavuzları esas alarak düzenlemelerini yapmalı ve tüm sağlık çalışanlarına KKE Kullanımı konusunda eğitim vermelidir. Hem teorik anlatım hem de pratik uygulama gösterimi ile desteklenerek verilen eğitimlerin hem bilinçli uygulama yapılmasına hem de hatalı uygulamaların önüne geçilmesinde katkı sağlayacağı açık bir gerçektir.

Kişisel koruyucu ekipman kullanımının doğru uygulanabilmesi için sağlık merkezlerinde yeterince kişisel koruyucu ekipman bulunması oldukça önemli bir husustur. DSÖ, sağlık merkezlerinde pandemi planı hazırlanırken, KKE tedariğinde ve sürekliliğinde aksaklık yaşanmaması için günlük KKE gereksinimi hesaplanmasını (kurumun yatak kapasitesi, kurumda çalışan sağılı personeli sayısı ve çalışma döngüsü dikkate alınarak) ve uygun miktarda stoklar oluşturtulmasını önermektedir (14). CDC, DSÖ, ECDC ve HSGM' nün yayınlamış olduğu kılavuzlar incelendiğinde, KKE ile ilgili tekrar kullanım stratejilerinin belirlendiği ve alternatif yöntemlerin önerildiği görülmüştür $(1,7,14,15,19-22)$. Personelin çalışma şeklinin düzenlenmesi, esnek çalışma düzeninin sağlanması, hasta bakımı esnasında enfekte olan personelin işe dönüş kriterlerinin belirlenmesi, merkezlerde devam eden hasta bakım sayılarının ve bakacak personel sayılarının kısıtlanması, acil olmayan ameliyatların ertelenmesi gibi düzenleyici önleyici faaliyetler göze çarpmaktadır $(15,23,24)$. Bu faaliyetler aynı zamanda sağlık merkezlerinde insan hareketliliğini kısıtlayarak, virüsün yayılım hızını da yavaşlatacak uygulamalar olması nedeni ile de önerilmektedir $(1,7,13)$.

DSÖ, CDC ve T.C. Sağlık Bakanlığı HSGM, sağlık merkezlerinde kullanılacak KKE ile ilgili olarak, box önlükleri ve gözlük/siperlikler için tekrar kullanılabilen, sıvı geçirimsiz, yıkanabilir ve dezenfekte edilebilir ürünleri önermiştir. N95 maskeler için de uzun süreli kullanım ve saklama koşulları oluşturmuşlardır $(1,12,16)$. Bu koşullar incelendiğinde, N95 maskelerin kullanılması esnasında, üzerine cerrahi/ tıbbi maske ya da siperlik takılarak maskelerin sıvı- sekresyon sıçramasından korunması ve maskelerin -hastalar arası geçiş de dahil olmak üzere- çıkarılmadan aktif 8 saat kullanılabileceği göze çarpmaktadır $(1,15,16)$. Aktif 8 saat kullanılmamış, tekrar kullanılabilecek şekilde korunmuş, niteliği bozulmamış ve kontamine olmamış N95 maskeler için, her kullanım sonrası arka bağlarından tutularak çıkarılması, hava alabilen kağıt torba ya da kağıt havlu gibi aparatlar ile saklanması, saklama torbaları/havlularının her kullanım sonrası değiştirilmesi ve koşullarına uygun olarak saklanan maskelerin 5 defadan fazla kullanımaması da öneriler arasında yer almaktadır $(15,16)$. Ayrıca, kontamine olmuş, hasarlı (yırtılma, bükülme vb.) ve nefes almada güçlük yaratan maskelerin tekrar kullanılması önerilmemektedir $(1,15,16,23,24)$.

\section{Çevresel Temizlik ve Dezenfeksiyon ílkeleri}

SARS-CoV-2 virüsünün çevresel yüzeylerden insanlara bulaşıp bulaşmadığına ilişkin yapılan çalışmalarda, virüsün cansız yüzeylerde canlılığını bir süre koruduğu $(22,25)$ ve çapraz yola insanlara bulaşabildiği ve çevresel yüzeylerin hastalığın yayılmasında rol oynadığı belirtilmektedir $(25,26)$. Bu nedenle hastalığının yayılımının önlenmesi için enfekte bireylerin bulunduğu odaların, kullandığı ekipmanların ve çevresinin mutlaka temizlenmesi ve dezenfekte edilmesi gerekmektedir $(2,3,7,21,22)$. Ayrıca, COVID-19 tanılı hastaların odasının temizliğe başlanmadan önce mutlaka havalandırıması gerektiği bildirilmektedir $(7,21)$. DSÖ ve CDC, bu havalandırma süresine ilişkin, hastanın odada geçirdiği sürenin ve odanın büyüklüğünün dikkate alınarak havalandırmanın farklı sürelerde sağlanabileceğini, bu nedenle havalandırmanın, hastaya yapılan işlem, hastanın odada kalış süresi, odada bulunan kişi sayısı ve odanın büyüklüğü vb. dikkate alınarak yeterli süre yapılmasını önermektedir $(14,21)$. Havalandırma sürelerine ilișkin literatürde net bir bilgiye ulaşılamamıștır. Fakat bazı kılavuzlarda merkezi havalandırma sistemleri kullanılan sağlık merkezlerinde, hasta odalarında, saatte 6-12 kez hava değişimi yapılmasının yeterli havalandırma sağlayacağı söylenmektedir $(14,21)$.

Temizlik ve dezenfeksiyon işlemini uygulayacak personelin, kişisel korunma önlemlerini bilmesi, kullanacağı ürün hakkında fikir sahibi olması ve temizlik ilkelerinin tüm basamaklarını eksiksiz yerine getirmesi son derece önemli bir husustur (7). Bu nedenle sağlık merkezlerinde EKK' leri tarafından verilen eğitimler ve yapılan denetimler kesintisiz sürdürülmeli, temizlik ve dezenfeksiyon işlemlerinin standardizasyonu sağlanmak amacıyla yazılı dokümanlar (talimatnameler) oluşturulmalıdır (7). Oluşturulan dokümanlarda temizlik ve dezenfeksiyon işlemlerine yönelik genel olarak; kullanı- 
lacak solüsyon ve miktarı, kullanım şekli, kullanım sıkığı vb. ilkeler yer almalıdır $(7,27,28)$. CDC, ECDC ve DSÖ 'ne göre kullanılacak temizlik/dezenfeksiyon solüsyonları, EPA (United States Environmental Protection Agency)' ya, ülkemizde ise Biyosidal Ürünler' e göre uygunluk belgesi olan ürünlerden tercih edilmelidir (27-30). Bu bağlamda, yüzey dezenfeksiyonunda kullanılacak ürünlerin başında; klor bileşikleri, hidrojen peroksit, hidrojen peroksit+perasetik asit kombinasyonları, quarterner amonyum bileşikleri, fenol türevleri ve alkol (\%70 etil alkol) yer almaktadır $(28,31)$. Klor bileşikleri ve alkol bazlı solüsyonlar hızlı etki süreleri, mikrobisidal etkinlikleri ve kolay ulaşılabilir olmaları nedeni ile en sık tercih edilen dezenfektanlardır. Ülkemizde de T.C. Sağlık Bakanlığı HSGM' nün yayınlamış olduğu rehberde, COVID-19 hastalarının tanı ve tedavilerinin sürdürüldüğü alanlarda temizlik ve dezenfeksiyon sağlanması için klor ve alkol içeren solüsyonların kullanılmasını önermektedir (7). COVID-19 hasta bakılan üniteler "Yüksek Riskli Alanlar" olarak kabul edilerek, temizlenecek alanın özelliğine göre klor solüsyonlarının, temizlik ve dezenfeksiyon için en az 500 ppm'lik, kan ve vücut sıvısı kontaminasyonu var ise 5000 ppm'lik klor konsantrasyonu dezenfeksiyon sağlanması önerilmektedir (7). Ayrıca rehberde gözlük ve siperlik gibi klor bileşiklerinin yapısına ve üretici önerisine uygun olmayan malzemeler (dijital ürünler, glikometre, akrilik yüzeyli ürünler vb.) için de en az \%70'lik etil alkol içeren alkol bazlı solüsyonların kullanılması önerilmektedir (7).

\section{Atık Yönetimi}

CDC önerileri doğrultusunda ülkemizde T.C. Sağlık BakanIığı HSGM tarafından KKE kullanımı sonrası bertarafı için yapılması gereken uygulamalar belirlenmiştir $(7,20)$. Bu uygulamalar, çok kullanımlık önlüklerin kullanım sonrasında hasta odasında uygun şekilde çıkarılarak kırmızı kovalar (tıbbi atık kovaları) içine atılması, ağzı kapatılarak yıkama ve termal dezenfeksiyon yapılmak üzere çamaşırhaneye gönderilmesi, kullanılan cerrahi/tıbbi maskelerin kulak arkasına geçirilen lastikli maske ise lastik kısımlarından tutularak, bağlamalı bir maske ise önce alt bağlarından ardından üst bağlarından çözülerek, çıkarılması ve tıbbi atık kovasına atılması şeklindedir $(15,19,20)$. Atıklardan bulaş henüz olarak kanıtlanmış olmasa da virüsün yüzeylerde canlı kalabildiği ve yayıldığı farklı çalışmalarla gösterilmiştir $(22,25,32)$. Bu nedenle atıklar toplanırken ve taşınırken bulaş ve yayılımın olmaması için azami özen gösterilmelidir. Atık personeli kişisel koruyucu ekipmanlarını giyinmeli ve atık toplama/ taşıma süresinde aerosol oluşturacak işlemlerden kaçınmaIıdır. Hastanelerde hastaların atıkları enfeksiyöz atık olarak kabul edilmeli ve bertarafı "Tıbbi Atık Yönetimi" ne uygun olarak yapılmalıdır (33).

\section{Destek Ünitelerinde Enfeksiyon Kontrolü}

Pandemi sürecinde sağlık merkezlerinde hizmet veren, çamaşırhane, merkezi sterilizasyon üniteleri, laboratuvarlar vb., hasta bakım aktiviteleri ile doğrudan ilişkili olmayan, fakat önlem alınmazsa hastalığın yayılımına dolaylı olarak neden olabilecek önemli ünitelerdir. Hastaların özellikle vücut sıvı ve sekresyonları ile kontamine olan materyallerin transfer edildiği bu alanlarda da öncelik çalışan sağlığının korunması ve çapraz bulaşın önlenmesinin sağlanmasıdır $(3,14)$. Bu nedenle destek ünitelerinde çalışan personelin mutlaka yukarıda belirtilen KKE kullanımına uyum göstermesi ve temizlik/dezenfeksiyon ilkelerini benimsemesi gerekmektedir $(1,15,34)$. Kontamine veya kullanılmış örtü, çarşaf ve giysiler çevreyi kontamine etmeyecek şekilde taşınmalı ve tekrar kullanım öncesi yıkama-dezenfeksiyon işleminden geçirilmelidir. Çamaşırlar toplanırken ve taşınırken cildin ve mukozanın korunmasına dikkat edilmeli, çamaşır torbaları COVID-19 hastalarının olduğu ünitelerden çıkarıııken sıkıca kapatılmalıdır. Çamaşırlar standart enfeksiyon kontrol prensiplerine göre güvenli olarak yıkanmalı ve ardından kontrolleri yapılarak tekrar ünitelere güvenli olarak transfer edilmelidir $(15,35)$. Aynı şekilde hastadan çıkan atıklar da kontaminasyona ve bulaşa neden olmayacak biçimde güvenli şekilde bertaraf edilmelidir (35).

\section{SONUÇ}

COVID-19 ile mücadele kapsamında sağlık kurumlarında ciddi önlemler alınmaktadır. Bu önlemlerin birçoğu hastalığın bulaşmasını önlemek amacı ile alınmış olsa da aynı zamanda hastalığın yayılımının önlenmesi ve hızının yavaşlatılması açısından da son derece önemlidir. 2019 yılı sonundan beridir mücadele edilen COVID-19 hastalığından korunmaya ilişkin veriler enfeksiyon kontrol önlemlerinin hastalığın bulaşının ve yayılımının önlenmesinde yeterli olabileceğini göstermektedir. Yalnızca sağlık hizmeti veren kurumlarda değil aynı zaman da toplumda da izolasyon önlemlerine (temas ve damlacık) uyulmasının, el hijyeni uygulamaları gibi temel korunma yöntemlerinin kullanılmasının hastalığın yayılımının önlenmesinde etkili olacağı düşünülmektedir.

\section{Teşekkür}

ZBEÜ Tıp Fakültesi Enfeksiyon Hastalıkları ve Klinik Mikrobiyoloji AD. ve ZBEÜ Sağlık Uygulama ve Araştırma Merkezi Enfeksiyon Kontrol Komitesi Başkanı Sayın Prof. Dr. Güven ÇELEBI' ye katkılarından dolayı teşekkür ederim.

\section{Yazar Katkı Beyanı}

$\mathrm{Bu}$ derlemenin tüm aşamaları yazar tarafından raporlandırılmıştır.

\section{Çıkar Çatışması}

Herhangi bir çıkar çatışması bulunmamaktadır.

\section{Finansal Destek}

$\mathrm{Bu}$ derleme için herhangi bir kurum veya projeden finansal destek alınmamıştır. 


\section{Etik Kurul Oluru}

Deneysel ve insan örneği çalışması olmadığından etik kurul oluru gerekmemiştir.

\section{Hakemlik Süreci}

Kör hakemlik süreci sonucunda yayınlanmaya uygun bulunmuş ve kabul edilmiştir.

\section{KAYNAKLAR}

1. World Health Organization (WHO, 27 February 2020). Rational use of personal protective equipment for coronavirus disease 2019 (COVID-19): interim guidance. pp. 1-7. https://apps.who. int/iris/bitstream/handle/10665/331215/WHO-2019-nCov-IPCPPE_use-2020.1-eng.pdf Erişim Tarihi: 18.03.2020

2. Centers for Disease Control and Prevention(CDC) (2003, updated-2019), Healthcare Infection Control Practices Advisory Committee (HICPAC): Guidelines for environmental infection control in health - care facilities (2003) https://www.cdc.gov/ infectioncontrol/guidelines/environmental/index.html

3. Interim Infection Prevention and Control Recommendations for Patients with Suspected or Centers for Disease Control and Prevention (CDC) (17 September 2020) Confirmed Coronavirus Disease 2019 (COVID-19) in Healthcare Settings 2020. https:// www.cdc.gov/coronavirus/2019-ncov/hcp/infection-controlrecommendations.html. Erişim tarihi:12.05.2020

4. Lai CC, Shih TP, Ko WC, Tang HJ, Hsueh PR. Severe acute respiratory syndrome coronavirus 2 (SARS-CoV-2) and coronavirus disease-2019 (COVID-19): The epidemic and the challenges. Int. J. Antimicrob. Agents, 2020;55(3):105924.

5. T.C. Sağlık Bakanlığı (11 Ağustos 2005). Yataklı Tedavi kurumları Enfeksiyon Kontrol Yönetmeliği. https://www. resmigazete.gov.tr/eskiler/2005/08/20050811-6.htm Erişim tarihi: 10.05 .2020

6. Cheng VCC, Wong SC, Chen JHK, Yip CCY, Chuang VWM, Tsang OTY, Sridhar S, Chan JFW, Ho PL, Yuen KY. Escalating infection control response to the rapidly evolving epidemiology of the Coronavirus disease 2019 (COVID-19) due to SARSCoV-2 in Hong Kong, Infect Control Hosp Epidemiol, 2020;41(5):493-498.

7. TC. Sağlık Bakanlığı Halk Sağlığı Genel Müdürlüğü (2 Nisan 2020). COVID-19 Rehberi. sf. 25, 2020.

8. World Health Organisation (WHO). Who Guidelines On Hand Hygiene In Health Care Summary ol. 30, no. 1, p. 64, 2017. https://www.who.int/gpsc/5may/tools/who_guidelineshandhygiene_summary.pdf Erişim tarihi; 15.05.2020

9. Hastane İnfeksiyonları Dergisi (2008) El Hijyeni Kılavuzu; 12:(Ek 1):3-21.

10. Centers for Disease Control and Prevention (CDC) (17 May 2020) Guidance for healthcare providers about hand hygiene and COVID-19 https://www.cdc.gov/coronavirus/2019-ncov/ hcp/hand-hygiene.html Erişim tarihi:19.05.2020

11. Centers for Disease Control and Prevention (CDC) Hand Hygiene Guidance https://www.cdc.gov/handhygiene/ providers/guideline.html Erişim tarihi:01.05.2020
12. World Health Organisation (WHO), İnection prevention and control. https://www.who.int/emergencies/diseases/novelcoronavirus-2019/technical-guidance/infection-preventionand-control Erişim tarihi:08.05.2020

13. Wang J, Zhou M, Liu F. Reasons for healthcare workers becoming infected with novel coronavirus disease 2019 (COVID-19) in China, J. Hosp. Infect., 2020;105(1): 100-101.

14. World Health Organization (WHO), Infection prevention and control during health care when COVID-19 is suspected, Clin. Chest Med., pp. 1-3, 2020.

15. Centre for Disease Control and Prevention (CDC), Use Personal Protective Equipment ( PPE) When Caring for Patients with Confirmed or Suspected COVID-19 ,pp. 1-2, 2020.

16. European Centre for Disease Prevention and Control (ECDC). Guidance for wearing and removing personal protective equipment in healthcare settings for the care of patients with suspected or confirmed COVID-19, ECDC Rep., no. February, pp. 1-13, 2020.

17. Tran K, Cimon K, Severn M, Pessoa-Silva C.L, Conly J. Aerosol generating procedures and risk of transmission of acute respiratory infections to healthcare workers: a systematic review, PLoS One, 2012;e35797.

18. Organización Mundial de la Salud, Advice on the use of masks in the context of COVID-19: interim guidance-2, Guía Interna la OMS, no. April, pp. 1-5, 2020.

19. European Centre for Disease Prevention and Control (ECDC) (8 April 2020). Using face masks in the community Reducing COVID-19 transmission from potentially asymptomatic or presymptomatic people through the use of face masks. https:// www.ecdc.europa.eu/sites/default/files/documents/COVID-19use-face-masks-community.pdf Erişim tarihi: 10.04.2020

20. T.C. Sağlık Bakanlığı (2020). N95/FFP2 Maskelerin Uzun Süre Kullanımı. https://covid19bilgi.saglik. gov.tr/depo/enfeksiyon-kontorl-onlemleri/COVID19N95-FFP2MaskelerinUzunSureKullanimi.pdf Erişim Tarihi:27.04.2020

21. Centre for Disease Control and Prevention (CDC); environmental Infection control guidelines-appendix b, https:// www.cdc.gov/infectioncontrol/guidelines/environmental/ appendix/air.html\#tableb2 Erişim tarihi:03.05.2020

22. Li R, Pei S, Chen B, Song Y, Zhang T, Yang W, Shaman J. Substantial undocumented infection facilitates the rapid dissemination of novel coronavirus (SARS-CoV2), 2020;493:489-493.

23. World Health Organization (WHO) (6 April 2020). Advice on the use of masks in the context of COVID-19: interim guidance. https://apps.who.int/iris/handle/10665/331693 Erişim tarihi: 10.04.2020

24. Centre for Disease Control and Prevention (CDC) (23 April 2020). Considerations for alternate care sites, https://www. cdc.gov/coronavirus/2019-ncov/hcp/alternative-care-sites.html Erişim tarihi:03.05.2020

25. Wang W, Xu Y, Gao R, Lu R, Han K, Wu G, Tan W. Detection of SARS-CoV-2 in different types of clinical specimens. JAMA, 2020;323(18):1843-1844.

26. van DN, Bushmaker T, Morris DH, Holbrook MG, Gamble A, Williamson BN, Tamin A, Harcourt JL, Thornburg NJ, Gerber SI, Lloyd-Smith JO, de Wit E, Munster VJ. Aerosol and surface stability of SARS-CoV-2 as compared with SARS-CoV-1. New England Journal of Medicine, 2020;382(16):1564-1567. 
27. World Health Organization (WHO) (21 March 2020). Infection prevention and control guidance for long-term care facilities in the context of COVID-19: interim guidance. https://apps.who. int/iris/handle/10665/331508 Erişim Tarihi: 25.03.2020

28. Disinfectants Use Against Sars-Cov-2 https://www.epa.gov/ pesticide-registration/list-n-disinfectants-use-against-sars-cov2-COVID-19 Erişim tarihi: 15.05.2020

29. Centre for Disease Control and Prevention (CDC). Cleaning and disinfecting your home. https://www.cdc.gov/coronavirus/2019ncov/prevent-getting-sick/disinfecting-your-home.html. Erişim Tarihi: 08.05.2020

30. European Centre for Disease Prevention and Control (ECDC) (26 Mar 2020). Disinfection of environments in healthcare and non- healthcare settings potentially contaminated with SarsCov2 Target audience Cleaning options for healthcare settings after the management of a suspected or confirmed case of COVID-19. https://www.ecdc.europa.eu/en/ publications-data/disinfection-environments-covid-19 Erişim Tarihi; 30.03.2020
31. Centre for Disease Control and Prevention (CDC). Cleaning disinfection. https://www.cdc.gov/coronavirus/2019ncov/ community/organizations/cleaningdisinfection.html. Erişim tarihi:11.05.2020

32. T.C. Sağlık Bakanlığı (2020). Enfeksiyon kontrol önlemleri. https://covid19bilgi.saglik.gov.tr/tr/enfeksiyon-kontrolonlemleri. Erişim tarihi: 09.05.2020

33. Yataklı Tedavi Kurumları Atık Yönetmeliği https://www. resmigazete.gov.tr/eskiler/2017/01/20170125-2.htm. Erişim tarihi: 15.05.2020

34. Güven B, Can M. COVID-19 pandemi sürecinde biyokimya laboratuvarı akış ve güvenlik prosedürleri: Zonguldak Bülent Ecevit Üniversitesi Tıp Fakültesi deneyimi. Batı Karadeniz Tıp Dergisi, 2020;4(2):39-43.

35. Zonguldak Bülent Ecevit Üniversitesi COVID-19 Eylem Planı http://cdn3.beun.edu.tr/ hastane/85b51c0f66c313d4d5ef7f75a4d20cae/covid19-eylemplani-12-mart-2020-son-pdf.pdf Erişim Tarihi: 15.05.2020 